\title{
CAZADORES RECOLECTORES DE LA BOCA DEL ESTUARIO DEL RÍO GALLEGOS, SANTA CRUZ, ARGENTINA
}

\author{
BETTINA ERCOLANO ${ }^{1}$ Y FLAVIA CARBALLO M. ${ }^{1}$
}

\begin{abstract}
RESUMEN
Se caracterizan las poblaciones de cazadores recolectores que habitaron el sur del estuario río Gallegos, cuenca hídrica más austral de Patagonia continental argentina. Se acota cronológicamente parte del espacio utilizado mediante el fechado de suelos, relaciones geomorfológicas y el análisis de los conjuntos líticos. Se evalúa el papel del estuario como concentrador de mayor actividad humana en comparación con espacios relativamente alejados del ámbito costero. Se concluye que el sector costero habría tenido un uso más intensivo que el resto del valle del río Gallegos y que a su vez, la costa del estuario fue ocupada más recurrentemente que el litoral atlántico. Estas ocupaciones pueden ser atribuidas a la parte final del Holoceno tardío.
\end{abstract}

PALABRAS CLAVES: Geoarqueología, Estuario del río Gallegos, Cazadores recolectores, Holoceno tardío.

\section{HUNTER GATHERERS AT THE RÍO GALLEGOS ESTUARY MOUTH, SANTA CRUZ, ARGENTINA}

\begin{abstract}
This contribution describes the populations of hunter-gatherer that inhabited the southern portion of the Río Gallegos estuary, the southernmost river basin of Argentinean continental Patagonia. Soil dating, geomorphological relationships, and the study of lithic assemblages are used to narrow down chronologically the use of space. The role of the estuary as a concentrator of human activity is evaluated by comparison to relatively distant upland spaces. We conclude that the coastal environment would have been used more intensively and recurrently than both the region upstream the Gallegos river and the neighbouring Atlantic coast. These occupations can be assigned to the terminal late Holocene.
\end{abstract}

KEY WORDS: Geoarchaeology, Río Gallegos estuary, Hunter gatherers, Late Holocene.

1 Centro de Investigación "Dra. Elsa Barbería” - Unidad Académica Río Gallegos, Universidad Nacional de la Patagonia Austral. Lisandro de la Torre 1070 - 9400 Río Gallegos, Santa Cruz, Argentina. E-mail: pi_costera@uarg.unpa.edu.ar 


\section{INTRODUCCIÓN}

Las poblaciones de cazadores recolectores que ocuparon la vasta costa de la provincia de Santa Cruz han recibido hasta hace relativamente poco tiempo escasa atención. De manera intermitente los trabajos dan comienzo en la década del 60', focalizando el estudio en identificar y fechar sitios costeros bajo una óptica que privilegiaba la ocupación estacional asociada a una movilidad cordillera-costa y el reconocimiento de una tecnología orientada a la explotación de recursos marinos (Cordeau 1965; Sanguinetti de Bórmida 1981; Gómez Otero y Fontanella 1981, entre otros). Recién a mediados de los 90' se inician investigaciones más prolongadas en el tiempo centradas en la costa norte (Castro y Moreno 2000; Castro et al. 2001; Castro et al. 2003, entre otros) y Cabo Vírgenes en el extremo sur de la provincia (Borrero y Franco 2000; L'Heureux y Franco 2002; L'Heureux et al. 2003, entre otros). Nuevas interrogantes han orientado estos trabajos más recientes hacia un cambio de escala espacial desde el sitio a una perspectiva regional y suprarregional. Las problemáticas se focalizan en los rangos de acción de los cazadores recolectores $y$, de qué manera y cuándo se produce la incorporación de la costa, con una mayor importancia de los recursos marinos en la dieta de estas poblaciones y un uso más prolongado de estos espacios (Moreno et al. 2000; Barberena 2002; L'Heureux et al. 2003). Como resultado de estos trabajos se advierten ciertas tendencias en los paisajes arqueológicos reconocidos para el norte y sur de la provincia de Santa Cruz. Comparativamente, la zona norte, entre el S del golfo de San Jorge hasta las inmediaciones de Punta Medanosa, muestra frecuencias artefactuales marcadamente mayores lo que implica un uso más intenso. Asimismo, la existencia de una alta densidad de estructuras tipo chenque habla de una funcionalidad diferente de ciertos sectores (Castro y Moreno 2000) en contraste con la gran uniformidad que se infiere en las actividades desarrolladas en el sur (Borrero y Franco 2000). Por otra parte, si bien las cronologías de las ocupaciones costeras corresponden al Holoceno tardío, en la zona norte de Santa Cruz, el sitio Cabo Tres Puntas podría remontarse al Holoceno medio (Castro y Moreno 1996-1998).

La escasa profundidad temporal de la mayoría de las ocupaciones costeras en relación con los fechados más tempranos de la región -nacientes del río Chico y Meseta Central ca. 11.000 años A.P (Bird 1993; Miotti 2000, respectivamente) y estancia Marcatch Aike, a $50 \mathrm{~km}$ al SO del área de estudio, con 6.930 años AP (Nami 1995, entre otros)- estaría, en parte, vinculada con la evolución geomorfológica del contorno costero, que estuvo sujeto a grandes fluctuaciones durante el Holoceno. La tendencia transgresiva que comenzara en el Pleistoceno Tardío y alcanzara un máximo ca. 6000 años AP (IPCC 2001) presupone la desaparición de vestigios de eventuales poblaciones tempranas relacionadas con riberas anteriores. A la fase de relativa estabilidad que siguió con posterioridad, se asocia la acreción de nuevos espacios costeros, topográficamente llanos, con alto potencial de ser progresivamente ocupados por las poblaciones humanas (por ejemplo: Punta Medanosa, Bahía Laura, margen S del estuario del río Gallegos, Punta Dungeness, etc.). Estos espacios de acreción holocénica no tienen una gran continuidad espacial a lo largo de la costa debido a las particularidades geológicas y estructurales de la misma, siendo lo usual la presencia de acantilados activos $e$ inactivos con resaltos que en ocasiones superan los $30 \mathrm{~m}$ de altura. No obstante, en las pendientes de estos acantilados son frecuentes los procesos de remoción en masa (Kokot y Codignotto 2002) lo que permite un tránsito relativamente sencillo ribera-continente. Idéntica funcionalidad de conexión tienen los numerosos cañadones que desde las áreas elevadas disectan las pendientes costeras. La casi totalidad de la cronología del registro arqueológico procedente de los terrenos holocénicos no va más allá de los 3.500 años AP, edades que son concordantes con las ocupaciones sobre acantilados (sitios arqueológicos en la estancia Cabo Buen Tiempo, Mansur-Franchomme 1988, Mansur et al. 2005) y cañadones (estancia Cabo Buen Tiempo, Miotti 1998; cañadón Gap, Franco com. pers.).

Específicamente, en la cuenca media e inferior del río Gallegos, los estudios realizados por nosotros dieron cuenta de un uso más intenso del ámbito costero, hecho que motivó el planteo de nuevas investigaciones que contemplaran en detalle el ecotono continente-mar (Carballo et al. 2000; Ercolano et al. 2000). Desde el punto de vista de las ocupaciones humanas las zonas de ecotono resultarían más atractivas en razón de la conjunción de recursos mixtos (Yesner 1980). 
El presente trabajo tiene por objetivo caracterizar a las poblaciones cazadoras recolectoras que habitaron la margen sur del río Gallegos, en las inmediaciones de su desembocadura, a través del análisis del material arqueológico relevado en superficie y a cielo abierto. Este río recorre de $\mathrm{O}$ a E el extremo austral de la provincia de Santa Cruz; con cabeceras en el piedemonte de la cordillera de los Andes desagua junto con el río Chico en el océano Atlántico, dando lugar a un estuario en forma de embudo.

El área analizada abarca una superficie aproximada de $40 \mathrm{~km}^{2}$ la cual puede verse en la Fig. 1. El carácter progradante de este sector de la costa abandonado paulatinamente por el agua, otorga la posibilidad de asignar una antigüedad relativa al registro arqueológico recuperado. La asignación de una cronología precisa de este registro es por el momento dificultosa habida cuenta de la poca disponibilidad de materiales datables. Se ha podido acotar cronológicamente parte del espacio utilizado mediante el fechado de suelos por metodologías radiocarbónica y de OCR (Oxidizable Carbon Ratio). Sobre la base de relaciones geomorfológicas y el análisis de los conjuntos líticos es posible realizar apreciaciones temporales tentativas. Por último, se evalúa el papel del estuario como concentrador de mayor actividad humana en comparación con espacios relativamente alejados del ámbito costero, como el valle medio del río Gallegos.

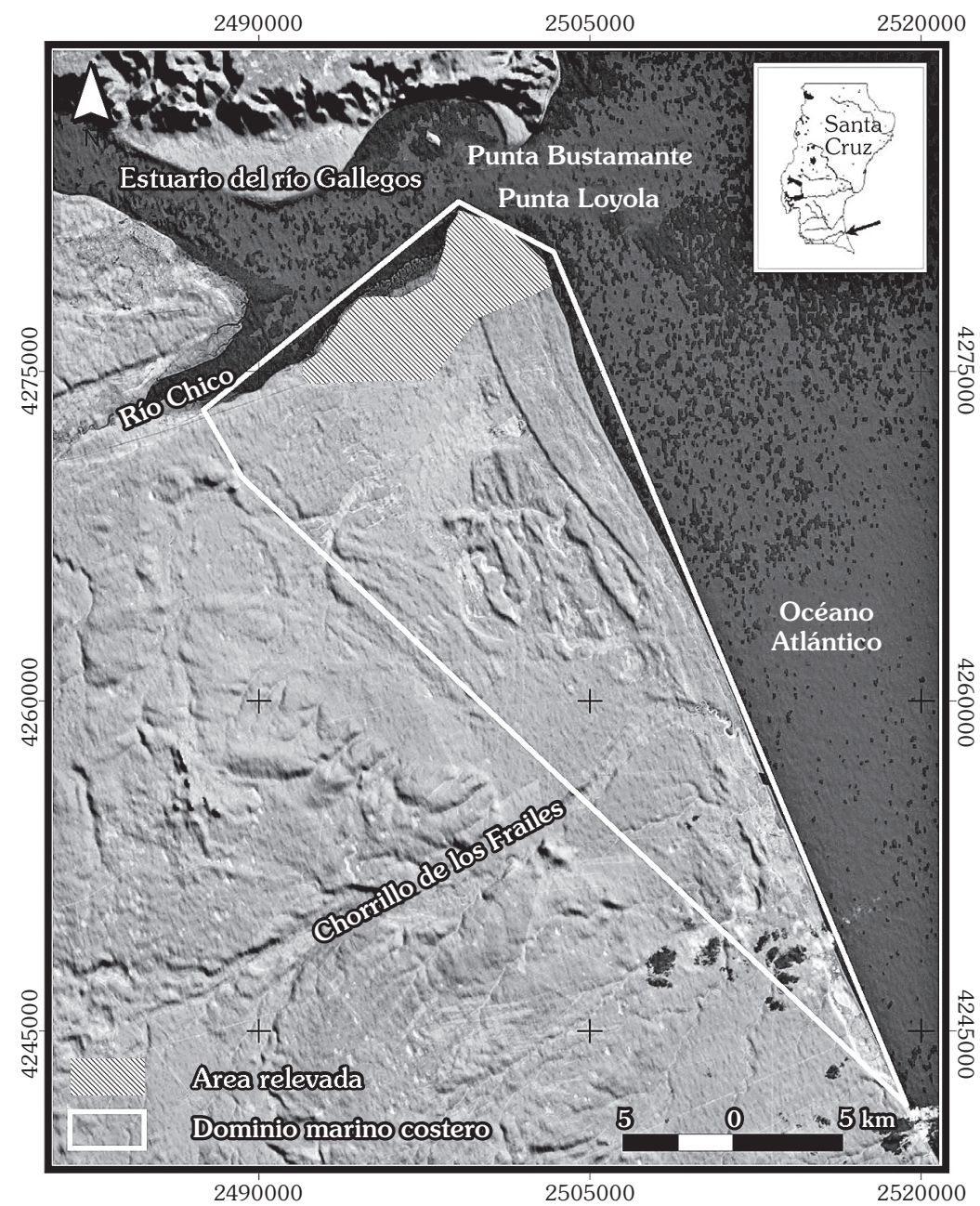

Fig. 1. Mapa de ubicación del área de estudio elaborado sobre imagen satelital Landsat 7 (año 2000) con realce. 


\section{METODOLOGÍA}

El uso de metodologías geológicas para responder interrogantes de índole arqueológica fue el marco para delinear este trabajo. A partir de fotografías aéreas pertenecientes al Servicio de Hidrografía Naval (escala 1:20.000) y al Instituto Nacional de Tecnología Agropecuaria (INTA) (escala 1:40.000) correspondientes a los años 1968 y 1999 , escaneadas y rectificadas, se reconocieron las distintas unidades morfoestratigráficas (geoformas) que tras el control de campo fueron volcadas en la Fig. 2. Un detallado relevamiento topográfico utilizando un geoposicionador geodésico Trimble 4600 SL con postproceso y como complemento un navegador satelital Garmin III plus, permitió establecer la altimetría de estas unidades. Las cotas obtenidas están referenciadas con respecto al mojón del Ministerio de Obras Públicas (MOP № 2866).

Una cronología de espacios relativa se obtuvo a partir de las relaciones de campo entre las diferentes geoformas y su comparación altimétrica con otras de litología equivalente pertenecientes a otros sectores costeros del sur de Patagonia con edades conocidas (Feruglio 1950; Codignotto et al. 1992; Rostami et al. 2000; González Bonorino 2002; entre otros). Se obtuvieron edades numéricas a partir de suelos desarrollados en varias de estas geoformas; la caracterización pedológica se realizó atendiendo a los criterios de campo de la Soil Taxonomy (Soil Survey Staff 1975).

El resultado de esta interpretación fue el soporte sobre el cual se diagramó el trabajo arqueológico. Sobre la base de la aplicación de una metodología distribucional (Dunnell y Dancey 1983) se efectuó el levantamiento de 28 transectas en las que se observó presencia o ausencia de material arqueológico, porcentaje de cobertura vegetal (visibilidad), materias primas líticas y alteración antrópica. Se recabó información adicional con fines estratigráficos en perfiles expuestos en canteras. Las transectas fueron conformadas por unidades de muestreo (UM) continuas, en su mayoría de $1000 \mathrm{~m}^{2}$ y orientadas tanto longitudinal como transversalmente a las geoformas (Fig. 2 y Tabla 1). El material lítico se clasificó siguiendo los lineamientos propuestos por Aschero (1975/revisión 1983), computando sólo aquellos artefactos que poseían talón (enteros y fragmentos proximales) y los instrumentos (Tabla 2).
En el análisis del registro arqueológico se contempló el impacto antrópico (total, parcial, nulo) producido por actividades de diversa naturaleza que afectan el área. Como consecuencia, la removilización de los materiales superficiales contribuye a su mezcla y dispara procesos erosivos, fundamentalmente eólicos, que favorecen aún más la formación de palimpsestos. Esto se tradujo en diferencias en los valores de densidad encontrados en una misma geoforma según se tratara de sectores alterados o no.

\section{GEOMORFOLOGÍA Y AMBIENTES}

Hacia el sur del estuario del río Gallegos se extiende un dominio marino de forma aproximadamente triangular caracterizado por un relieve ondulado con un suave gradiente hacia el litoral marítimo y cotas máximas de $25 \mathrm{~m}$ (Fig. 1). Distantes a unos 10 $\mathrm{km}$ en línea recta de la costa actual se encuentran los afloramientos de cordones litorales (Cordones Litorales I) más antiguos, asignados al Sangamon (Codignotto y Ercolano 2002). En sucesión hacia el $\mathrm{E}$, se localizan otras dos series de cordones litorales (Cordones Litorales II y III; Fig. 2), elongados en sentido NNO-SSE, que restringieron parcialmente sectores de la costa permitiendo la formación de paleoalbuferas entre éstos y el continente, tanto durante el Pleistoceno tardío como en el Holoceno. Los cordones más nuevos (Cordones Litorales III) pudieron ser asignados al final del Holoceno tardío a partir de un fechado radiocarbónico (ver más adelante Sector CLA- Paleoalbufera).

La red de drenaje es efímera, integrada por cañadones poco profundos. Procesos de naturaleza eólica originan tanto rasgos de erosión que se expresan en superficies de deflación y pequeñas cuencas endorreicas, así como también formas de acumulación tales como montículos y mantos discontinuos de arena.

Dentro de este marco general el ambiente costero, objeto del presente estudio, abarca los terrenos ubicados inmediatamente al sur del estuario, entre la desembocadura del río Chico y el océano Atlántico (Figs. 1 y 2). El área está expuesta a un régimen de mareas semidiurno de carácter macromareal, con rangos extremos que alcanzan valores medios para sicigias y cuadraturas de 9,5 y $5,4 \mathrm{~m}$ respectivamente. Se pueden distinguir entonces, 
un ambiente estuárico dominado por la dinámica de mareas y el litoral marítimo donde la acción de las mareas se conjuga con una fuerte energía de olas. Las diferencias señaladas repercutirán sobre el registro arqueológico.

Los estuarios son ambientes costeros depositacionales influenciados por procesos fluviales, régimen de olas y energía de mareas, donde es frecuente que se desarrollen marismas bajo regímenes macromareales (Boyd et al. 1992, entre otros). Estas últimas, se originan en sectores protegidos de las olas donde la marea penetra lentamente fluyendo en forma laminar, de modo que los sedimentos finos (limo-arcillosos) transportados por el agua se depositan progresivamente conformando un ambiente apto para el desarrollo de comunidades vegetales y animales. Estos ambientes se relacionan morfológicamente con planicies de marea que ocupan una posición topográfica más baja y cercana al agua. Tanto en marismas como planicies de marea prevalece la depositación sobre la erosión, aun en eventos de alta energía como las tormentas (Pethick 1992), concentrándose esta última en canales y pequeños cañadones.

A nivel mundial los estuarios han alcanzado su forma presente tras el acelerado ascenso del nivel del mar (10 mm/año, IPCC 2001) motivado por la deglaciación que siguió al último máximo glaciario ca. 22000 años AP (Chapell y Woodroffe 1992). Esta acelerada tendencia transgresiva prosiguió durante el Holoceno temprano alcanzando un máximo que fluctúa, según los autores y el sector estudiado de la costa patagónica, entre los 8.000 y 6.200 años AP (Codignotto et al. 1993 y Rostami et al. 2000, entre otros). Desde hace unos 3.000 años AP esta tasa de ascenso cae considerablemente a unos 0.5 $\mathrm{mm}$ /año y continúa en franca disminución - 0.1 a 0.2 $\mathrm{mm}$ /año- (IPCC 2001) hasta hace aproximadamente unos 300 años (Rivas y Cendrero 1995), donde esta tendencia se revierte verificándose un ascenso promedio de $1.5 \mathrm{~mm} / \mathrm{año} \mathrm{(IPCC} \mathrm{2001).}$

Para el estuario del río Gallegos y más específicamente para Punta Bustamante, que enmarca la boca en su margen $\mathrm{N}$, fechados radimétricos sobre conchillas provenientes de cordones litorales regresivos aportan una edad ca. 6700 años ${ }^{14} \mathrm{C}$ AP (González Bonorino 2002) (Fig. 1). Puede interpretarse entonces que estos depósitos marcarían el inicio de una fase de relativa estabilidad del nivel del mar.
Distribución actual de los recursos

El extremo sur de Patagonia está caracterizado por un clima templado frío y semiárido, donde las medias anuales de precipitación son de unos $250 \mathrm{~mm}$ y las temperaturas promedio de verano e invierno son del orden de $12^{\circ} \mathrm{C}$ y $2^{\circ} \mathrm{C}$ respectivamente. Durante casi todo el año dominan los vientos del oeste con velocidades mayores a 30 $\mathrm{km} / \mathrm{h}$ y ráfagas de más de $100 \mathrm{~km} / \mathrm{h}$ especialmente durante el mes de octubre. La vegetación que se adapta a estas condiciones climáticas conforma un ecosistema de estepa magallánica seca dominada por coirón fueguino (Festuca grascillima) (Cuadra y Oliva 1996). En el área bajo análisis, las geoformas constituidas por rodados (cordones litorales y espigas) presentan por lo general una cobertura graminosa con arbustos aislados, mientras que en aquellas geoformas conformadas por materiales finos (marisma y paleoalbufera) predominan las especies arbustivas.

La severidad del clima determina los patrones de distribución estacional de los principales grupos de vertebrados. Los ambientes abiertos, son habitados por choiques (Pterocnemia pennata), guanacos (Lama guanicoe), zorros colorados (Pseudalopex culpaeus), peludos (Chaetophractus villosus) y piches (Zaedyus pichiy). El ambiente marino abierto y el estuárico están caracterizados por mamíferos, principalmente cetáceos-, y distintas especies de bivalvos Mytilus chilensis y Patinigera magallanica (Isla Vera 2004), y gastrópodos.

Debido al ingreso de la marea a través del estuario, los ríos Gallegos-Chico y el Chorrillo de los Frailes sólo proveen agua dulce a partir de algunas decenas de kilómetros aguas arriba de sus desembocaduras. En el estuario del río Gallegos se verifican actualmente valores de salinidad altos para el consumo humano $(15 / 000)$, aun en la ciudad homónima distante unos $15 \mathrm{~km}$ de la boca (JMB-JICA 2004). Fuentes de carácter estacional son los numerosos bajos de distribución más o menos homogénea y de dimensiones relativamente pequeñas ( $1 \mathrm{~km}$ de diámetro) que se encuentran en el interfluvio de los cursos de agua mencionados. Estos bajos coinciden con paleolíneas de costa conformando un patrón alineado según el sentido de los antiguos rasgos costeros (NNO$\mathrm{SSE}$ ). Se caracterizan por una gran variabilidad 


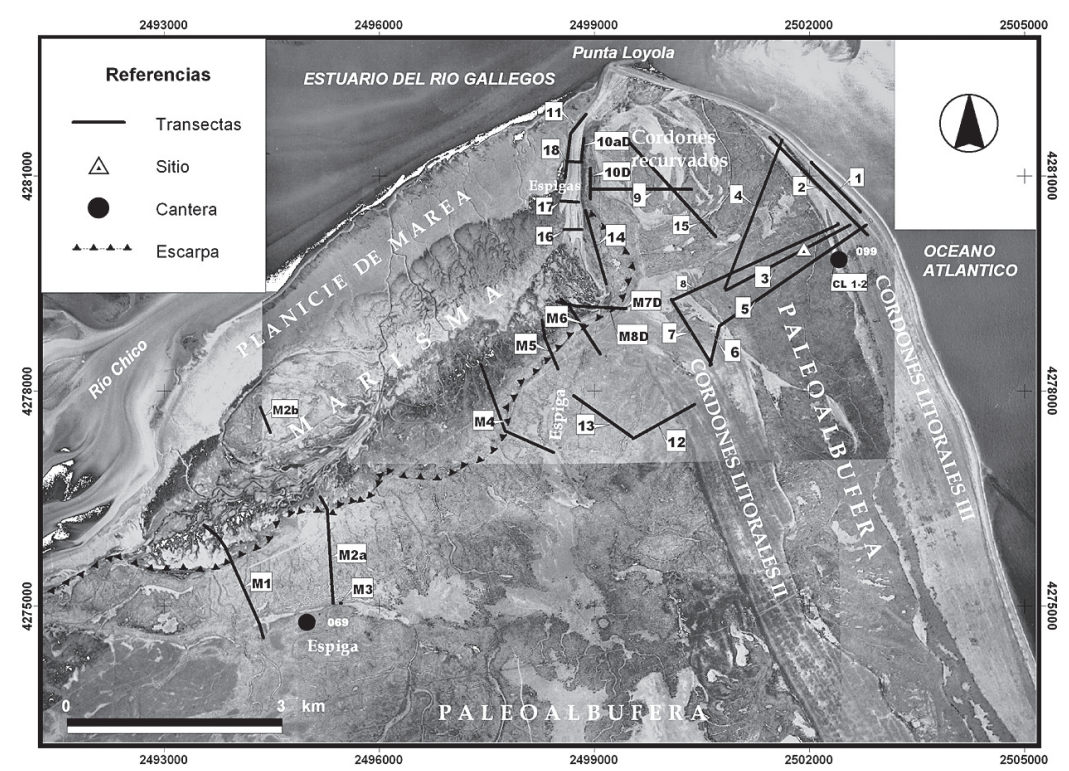

Fig. 2. Localización de los puntos de muestreo volcados sobre mosaico elaborado a partir de fotografías aéreas del INTA (año 1968).

hídrica interanual (Mazzoni et al. 2003), de modo que la predictibilidad de este recurso disminuye considerablemente.

La materia prima lítica utilizada para la confección de artefactos se encuentra disponible localmente en canteras secundarias bajo la forma de rodados de tamaño mediano a pequeño expuestos en varias de las geoformas del área (espigas, bancos de grava, playas del estuario y litoral marino). Se trata preferentemente de basalto y dacita que en conjunto conforman el 95\% de la muestra (Carballo Marina y Ercolano 2003). La fuente de proveniencia son rodados fluvioglaciales transportados desde el sector cordillerano por las aguas de fusión asociadas a los distintos eventos glacigénicos que afectaron al sur de Patagonia durante el Plio-Pleistoceno. La distribución es homogénea, el acceso a ella es sencillo y sin restricciones estacionales.

Dado que en los terrenos estudiados no afloran rocas duras del sustrato que puedan dar lugar a la génesis de cuevas o aleros, sólo las suaves lomadas que caracterizan a este paisaje costero podrían haber provisto reparo natural.

Sobre la base de la disponibilidad actual de recursos en un ambiente geomorfológico con escasas diferencias altimétricas, puede proponerse la posibilidad del uso anual del espacio estudiado por parte de las poblaciones humanas.

\section{EL PAISAJE ARQUEOLÓGICO SEGÚN LAS UNIDADES MORFOESTRATIGRÁFICAS}

Es necesario enfatizar el impacto antrópico reciente que presenta en general toda el área estudiada y en particular su extremo $\mathrm{N}$, que corresponde al sector de Punta Loyola (Fig. 2). No sólo se trata de un área utilizada con fines recreativos, debido a su cercanía a la ciudad de Río Gallegos, sino también porque es el lugar de emplazamiento de diversas obras de infraestructura: un puerto con instalaciones para almacenamiento de carbón y petróleo, viviendas precarias, poliductos, una ruta, numerosos caminos vecinales y canteras de extracción de áridos.

Nuestras investigaciones en la cuenca inferior del río Gallegos mostraron valores de densidad artefactual regional con un orden de magnitud de $10^{-4}$ que son coincidentes con la señalada para el extremo sur de la provincia de Santa Cruz (Belardi y Borrero 1999; Espinosa et al. 2000; Carballo Marina et al. 2000; Franco 2002; Carballo Marina y Ercolano 2003, entre otros). Por otra parte, pusieron en evidencia que las mayores frecuencias se daban en la costa (Carballo Marina et al. 2000; Ercolano et al. 2000). Al reducir la escala espacial al ambiente costero se advirtió en forma preliminar que en el estuario se daban densidades más altas que en el litoral atlántico (Carballo y Ercolano 2001). 
A fin de precisar las causas de estas variaciones en las frecuencias se plantearon nuevos muestreos en la costa cuyos resultados son los que se discuten en este trabajo.

En principio se esperaba que el pico de frecuencia artefactual detectado para el área costera en relación con el interior del continente, se correlacionara con una mayor riqueza artefactual producto de la explotación de recursos más diversos.

Otra de las expectativas que guiaron este trabajo era obtener mayores frecuencias artefactuales en las geoformas más antiguas y por lo tanto, en virtud del carácter progradante del espacio estudiado, disponibles desde hace más tiempo para la ocupación humana.

Por otra parte y a fin de constatar el uso más intensivo del estuario versus el litoral atlántico se desdobló el área en dos sectores: Costa del Estuario (CE) y Costa del Litoral Atlántico (CLA). A los efectos de facilitar las comparaciones se muestrearon superficies prácticamente equivalentes en ambos, correspondiendo a CE $141.500 \mathrm{~m}^{2}$ y a CLA 153.000 $\mathrm{m}^{2}$. Se tuvo en consideración para esta evaluación que en buena medida el registro arqueológico está afectado por acción antrópica, razón por la cual se plantearon transectas dirigidas y no dirigidas.

Los resultados se discriminan a continuación según la división mencionada y por unidades morfoestratigráficas ordenadas en forma decreciente de antigüedad. En la Tabla 1 se los presenta en forma sintética. En la Tabla 2 se enumeran las clases artefactuales siguiendo los criterios adoptados en la tabla anterior.

\section{Sector Costa del Estuario (CE)}

En los $141.500 \mathrm{~m}^{2}$ relevados se detectó un total de 1383 artefactos.

\section{Cordones Litorales II}

Afloran en la porción SE del sector, elevándose a cotas que rondan los $14 \mathrm{~m}$. Se trata de una serie de cordones litorales de disposición prácticamente meridiana que se prolongan hacia el S unos $15 \mathrm{~km}$, donde sus cotas alcanzan $17 \mathrm{~m}$. Las diferencias altimétricas pueden explicarse por fenómenos erosivos. Los cordones son de gravas gruesas a medianas con matriz sabulítico-arenosa sobre los que se desarrolla una densa y continua cobertura vegetal de gramíneas. Las líneas de drenaje son efímeras y discurren a lo largo de los senos de los cordones denotando un claro control morfológico. Estos rasgos superficiales así como también su altimetría permitirían atribuirle una génesis preholocénica.

En el caso de esta unidad es posible individualizar diferencias en las frecuencias artefactuales a partir del grado de alteración antrópica. La densa cobertura vegetal de gramíneas resulta la principal variable para explicar la ausencia de hallazgos en aquellas porciones de la unidad sin perturbación. Mientras que órdenes de magnitud de $10^{-4}$ (T № 6) y $10^{-3}$ ( T No 12 ) se vinculan a UM de estas transectas que interceptan sectores parcialmente disturbados, por ejemplo postes de alambrado. Las mayores densidades corresponden a órdenes de magnitud de $10^{-2}$ y se dan en coincidencia con una cantera de explotación de áridos próxima al resalto $(4 \mathrm{~m})$ que conecta a esta unidad con la marisma (Fig. 2). El desnivel propicia la formación de dunas rampantes a las que sólo se asocian materiales arqueológicos en superficie. El análisis de densidad artefactual no muestra diferencia entre la duna y la fosa de explotación de la cantera (T № M7D y M8D). La relación de hallazgos con distintas obras de naturaleza antrópica hace presuponer que buena parte del registro de esta unidad se halla contenido en el horizonte superficial del suelo.

Las clases artefactuales recuperadas son lascas, núcleos y raederas manufacturadas sobre las materias primas líticas de más alta disponibilidad (basalto y dacita). Estos hallazgos se ajustan al "ruido de fondo arqueológico" del valle medio e inferior del río Gallegos (Carballo et al. 2000).

\section{Paleoalbufera}

Hacia el E de los Cordones Litorales II se presentan extensos afloramientos de sedimentitas limoarcillosas que se prolongan en igual sentido que éstos, por varios kilómetros en dirección meridiana. Representan condiciones de depositación en un ambiente de baja energía de tipo albuférico. Las cotas fluctúan en los 9,50 m en vecindad del resalto de 1,50 m que conecta la Marisma ubicada al NO. Hacia el interior del continente las cotas de esta unidad ascienden lentamente hasta alcanzar unos $12 \mathrm{~m}$. 
Tabla 1. Información distribucional según unidades morfoestratigráficas.

\begin{tabular}{|c|c|c|c|c|c|c|c|c|}
\hline Geoforma & $\begin{array}{l}\mathrm{T} . \\
(\mathrm{N}=)\end{array}$ & $\begin{array}{c}\% \\
\text { Vegetación }\end{array}$ & $\begin{array}{l}\text { Alteración } \\
\text { Antrópica }\end{array}$ & UM & FA & $\begin{array}{c}\delta \\
\left(\mathrm{m}^{2}\right)\end{array}$ & $\begin{array}{c}\text { UM con } \\
\text { Hallazgos } \\
(\%)\end{array}$ & \\
\hline \multicolumn{9}{|c|}{ Costa del Estuario $\left(\mathrm{n}=1383\right.$; superficie $\left.=141.500 \mathrm{~m}^{2}\right)$} \\
\hline $\begin{array}{l}\text { Cordones litorales II } \\
\text { (¿Preholocénico?) }\end{array}$ & $\begin{array}{c}6 \\
7 \\
12 \\
\text { M6 } \\
\text { M7D } \\
\text { M8D }\end{array}$ & $75 / 100$ & $\begin{array}{c}\text { parcial } \\
\text { nulo } \\
\text { parcial } \\
\text { nulo } \\
\text { total } \\
\text { total }\end{array}$ & $\begin{array}{c}9 \\
13 \\
3 \\
1 \\
2 \\
2^{* *}\end{array}$ & $\begin{array}{c}3 \\
0 \\
8 \\
0 \\
55 \\
55\end{array}$ & $\begin{array}{c}3,3.10^{-4} \\
0 \\
2,6 \cdot 10^{-3} \\
0 \\
2,8 \cdot 10^{-2} \\
5,5 \cdot 10^{-2}\end{array}$ & $\begin{array}{c}33 \\
0 \\
67 \\
0 \\
100 \\
100\end{array}$ & 28 \\
\hline Paleoalbúfera & $\begin{array}{l}\text { M1 } \\
\text { M2a } \\
\text { M2b } \\
\text { M3D } \\
\text { M4 } \\
\text { M5 } \\
\text { M6 } \\
\text { M7D } \\
12 \\
13\end{array}$ & $0 / 100$ & nulo & $\begin{array}{c}11 \\
7 \\
3 \\
1 \\
6 \\
2 \\
1 \\
1 \\
7 \\
10\end{array}$ & $\begin{array}{c}58 \\
253 \\
1 \\
200 \\
15 \\
0 \\
26 \\
35 \\
7 \\
10\end{array}$ & $\begin{array}{c}5,3 \cdot 10^{-3} \\
3,6 \cdot 10^{-2} \\
3,0.10^{-4} \\
2,0.10^{-1} \\
2,5 \cdot 10^{-3} \\
0 \\
2,6.10^{-2} \\
3,5 \cdot 10^{-2} \\
1,0.10^{-3} \\
1,1 \cdot 10^{-3}\end{array}$ & $\begin{array}{c}73 \\
71 \\
33 \\
100 \\
33 \\
0 \\
100 \\
100 \\
57 \\
50\end{array}$ & 61 \\
\hline Marisma & $\begin{array}{c}\text { M1 } \\
\text { M2a } \\
\text { M4 } \\
\text { M5 } \\
\text { M6 } \\
\text { M7D }\end{array}$ & $25 / 100$ & nulo & $\begin{array}{c}2 \\
4 \\
10 \\
4 \\
4 \\
5\end{array}$ & $\begin{array}{c}1 \\
13 \\
133 \\
66 \\
98 \\
31\end{array}$ & $\begin{array}{l}5,0 \cdot 10^{-4} \\
1,9 \cdot 10^{-3} \\
1,3 \cdot 10^{-2} \\
1,7 \cdot 10^{-2} \\
2,5 \cdot 10^{-2} \\
6.2 \cdot 10^{-3}\end{array}$ & $\begin{array}{l}50 \\
25 \\
90 \\
75 \\
50 \\
40\end{array}$ & 62 \\
\hline $\begin{array}{l}\text { Espiga interna } \\
\text { (Edad mínima: } \\
306 \text { años AP) }\end{array}$ & $\begin{array}{c}10 \mathrm{D} \\
14 \\
10 \mathrm{aD}\end{array}$ & $\begin{array}{c}0 / 100 \\
75 / 100 \\
0 / 25\end{array}$ & $\begin{array}{l}\text { total } \\
\text { parcial } \\
\text { total }\end{array}$ & $\begin{array}{l}5^{*} \\
11 \\
6^{* *}\end{array}$ & $\begin{array}{c}71 \\
77 \\
164\end{array}$ & $\begin{array}{l}9,5 \cdot 10^{-3} \\
6,9 \cdot 10^{-3} \\
2,8 \cdot 10^{-1}\end{array}$ & $\begin{array}{c}80 \\
73 \\
100\end{array}$ & 79 \\
\hline Espigas externas & $\begin{array}{l}16 \\
17 \\
18\end{array}$ & $\begin{array}{c}0 / 25 \\
50 / 100 \\
50 / 75\end{array}$ & $\begin{array}{c}\text { parcial } \\
\text { total } \\
\text { total }\end{array}$ & $\begin{array}{l}2 \\
2 \\
2\end{array}$ & $\begin{array}{l}1 \\
0 \\
2\end{array}$ & $\begin{array}{c}5,0.10^{-4} \\
0 \\
1,0.10^{-3}\end{array}$ & $\begin{array}{c}50 \\
0 \\
50\end{array}$ & 33 \\
\hline Playa & 11 & 0 & nulo & 10 & 0 & 0 & 0 & \\
\hline \multicolumn{9}{|c|}{ Costa del Litoral Atlántico $\left(\mathrm{n}=325\right.$; superficie $\left.=153.000 \mathrm{~m}^{2}\right)$} \\
\hline $\begin{array}{l}\text { Cordones de Grava } \\
\text { Recurvados } \\
\text { (ca. } 6700 \mathrm{AP} \text { ) }\end{array}$ & $\begin{array}{c}9 \\
15\end{array}$ & $0 / 75$ & $\begin{array}{l}\text { parcial } \\
\text { parcial }\end{array}$ & $\begin{array}{l}4 \\
2\end{array}$ & $\begin{array}{l}0 \\
0\end{array}$ & $\begin{array}{l}0 \\
0\end{array}$ & \multicolumn{2}{|c|}{$\begin{array}{l}0 \\
0\end{array}$} \\
\hline Paleoalbúfera & $\begin{array}{c}3 \\
4 \\
5 \\
8 \\
9 \\
15\end{array}$ & $0 / 100$ & $\begin{array}{c}\text { nulo } \\
\text { nulo } \\
\text { nulo } \\
\text { nulo } \\
\text { parcial } \\
\text { parcial }\end{array}$ & $\begin{array}{c}13 \\
16 \\
19 \\
20 \\
8 \\
12\end{array}$ & $\begin{array}{c}247 \\
8 \\
0 \\
0 \\
0 \\
0\end{array}$ & $\begin{array}{c}1,9.10^{-2} \\
5,0.10^{-4} \\
0 \\
0 \\
0 \\
0\end{array}$ & $\begin{array}{c}54 \\
25 \\
0 \\
0 \\
0 \\
0\end{array}$ & 12,5 \\
\hline $\begin{array}{l}\text { Cordones litorales III } \\
\text { (Edad máxima: } \\
1348-1683 \\
\text { años AP) }\end{array}$ & $\begin{array}{c}2 \\
3 \\
4 \\
5 \\
8 \\
\text { CL1D } \\
\text { CL2D }\end{array}$ & $\begin{array}{c}0 / 100 \\
0 \\
100\end{array}$ & $\begin{array}{c}\text { parcial } \\
\text { parcial } \\
\text { nulo } \\
\text { parcial } \\
\text { parcial } \\
\text { total } \\
\text { total }\end{array}$ & $\begin{array}{c}20 \\
6 \\
4 \\
3 \\
6 \\
6 \\
4\end{array}$ & $\begin{array}{c}0 \\
0 \\
3 \\
0 \\
0 \\
63 \\
4\end{array}$ & $\begin{array}{c}0 \\
0 \\
7,5.10^{-4} \\
0 \\
0 \\
1,1.10^{-2} \\
1.10^{-3}\end{array}$ & $\begin{array}{c}0 \\
0 \\
67 \\
0 \\
0 \\
83 \\
25\end{array}$ & 18 \\
\hline Playa & 1 & 0 & parcial & 10 & 0 & 0 & 0 & \\
\hline
\end{tabular}

Referencias: T: Transecta; D: Dirigida; *: $15 \mathrm{~m}$ ancho; ${ }^{* *}: 5 \mathrm{~m}$ ancho; FA: Frecuencia Artefactual 
Tabla 2. Frecuencias artefactuales discriminadas por clases y unidades morfoestratigráficas.

\begin{tabular}{|l|c|c|c|c|c|c|c|c|c|c|}
\hline & \multicolumn{4}{|c|}{ Costa del Estuario } & \multicolumn{5}{c|}{ Costa del litoral Atlántico } \\
\hline $\begin{array}{c}\text { Geofes / } \\
\text { Geormas }\end{array}$ & $\begin{array}{c}\text { Esp. } \\
\text { Externas }\end{array}$ & $\begin{array}{c}\text { Esp. } \\
\text { Interna }\end{array}$ & Marisma & $\begin{array}{c}\text { Paleo } \\
\text { albúfera }\end{array}$ & CL II & $\begin{array}{c}\text { Playa } \\
\text { Atlántico }\end{array}$ & CL III & $\begin{array}{c}\text { Paleo } \\
\text { albúfera }\end{array}$ & $\begin{array}{c}\text { Cord. } \\
\text { Rec. }\end{array}$ & $\begin{array}{c}\text { Total } \\
\text { Lasca }\end{array}$ \\
\hline Núcleo & 0 & 265 & 315 & 547 & 98 & 0 & 58 & 248 & 0 & 1534 \\
\hline Raedera & 0 & 15 & 4 & 9 & 10 & 0 & 4 & 2 & 0 & 44 \\
\hline Raspador & 0 & 3 & 1 & 22 & 1 & 0 & 0 & 1 & 0 & 28 \\
\hline Preforma bifacial & 0 & 4 & 5 & 3 & 1 & 0 & 1 & 0 & 0 & 14 \\
\hline Punta proyectil & 0 & 0 & 1 & 1 & 0 & 0 & 0 & 1 & 0 & 3 \\
\hline Instrumento frag. & 0 & 0 & 2 & 1 & 0 & 0 & 0 & 0 & 0 & 3 \\
\hline Yunque & 0 & 2 & 0 & 0 & 0 & 0 & 0 & 0 & 0 & 2 \\
\hline Preforma de bola & 0 & 0 & 0 & 0 & 0 & 0 & 0 & 1 & 0 & 1 \\
\hline Cepillo & 0 & 0 & 0 & 1 & 0 & 0 & 0 & 0 & 0 & 1 \\
\hline Lasca con retoque & 0 & 3 & 3 & 0 & 2 & 0 & 1 & 0 & 0 & 9 \\
\hline Lámina & 0 & 0 & 0 & 1 & 0 & 0 & 0 & 0 & 0 & 1 \\
\hline TOTAL & 3 & 313 & 342 & 604 & 121 & 0 & 70 & 255 & 0 & 1707 \\
\hline
\end{tabular}

Referencias: Esp.: Espigas; CL: Cordones Litorales; Cord. Rec.: Cordones Recurvados.

El relevamiento comprendió sólo la porción aledaña a la Marisma que se halla enmarcada por dos espigas recurvadas y cuya superficie se encuentra disectada por numerosos paleocanales de marea orientados en dirección al estuario (Fig. 2). Las espigas de no más de $3 \mathrm{~m}$ de altura progradaron hacia el interior del continente sugiriendo una penetración de agua proveniente del estuario. En virtud de estas características morfológicas, el sector de Paleoalbufera considerado pudo haber sido ocupado alternativamente por el agua durante la transgresión holocénica, conformando un ambiente intermareal semejante al de la marisma actual (Perillo et al. 1996). La Paleoalbufera es hoy un ambiente netamente supratidal a juzgar por la vegetación que la coloniza y que a excepción de las especies halófitas, es semejante aun en su distribución a las presentes en el segmento superior de la Marisma (ver más abajo).

La frecuencia artefactual de la Paleoalbufera asciende a 604 artefactos y es la más alta de toda el área de estudio. La densidad se ubica, en general, en valores superiores al orden de magnitud regional y se distribuye en forma homogénea a juzgar por el $61 \%$ UM con hallazgos. Este resultado se apoyaría en los siguientes argumentos: a) se trata de una geoforma sin alteración antrópica, b) la visibilidad arqueológica es buena debido a un desarrollo edáfico incipiente que sustenta vegetación distribuida en parches, y c) ausencia de significativos procesos de enterramiento dado que bajo un clima semiárido los materiales gruesos experimentarían un ascenso vertical (Waters 1996); en este sentido la observación de un perfil expuesto en una cantera no mostró material arqueológico contenido en capa (Cantera 069, Fig. 2).

Dentro de esta unidad las densidades más altas se dan en cercanía a geoformas aptas para su uso como canteras. Un valor del orden de magnitud de $10^{-1}$ proviene de la transecta № M3D ubicada al pie de la espiga que flanquea a la Paleoalbufera por el oeste. Otros picos de densidad significativos se obtuvieron en el contacto paleoalbufera/marisma superior donde se localizan bancos de grava ( $\mathrm{T}$ № M2a) (ver: Marisma).

La alta frecuencia de raspadores $(n=22)$ es el rasgo más destacado del conjunto lítico de esta unidad. Aquí, se invierte la relación raedera/raspador $>1$ que caracteriza al registro arqueológico del valle medio e inferior del río Gallegos. Otra particularidad referida a estos instrumentos es que 16 de ellos aparecen concentrados en una sola UM de la T № M2a que corresponde al contacto paleoalbufera/marisma superior.

Todos los raspadores presentan filo frontal corto, son de tamaño pequeño y están elaborados en basalto a excepción de uno en calcedonia. Los de basalto han sido manufacturados en forma expeditiva, carecen de signos de reactivación, advirtiéndose además una alta tasa de abandono en el lugar. La alta frecuencia de raspadores en basalto habla de una gran disponibilidad de esta materia prima en el área 
y su uso oportunista. Por su parte, el confeccionado en calcedonia está muy reactivado, hecho también observado fuera de transecta en otros raspadores de esta materia prima. Para la costa norte del estuario (zona de Punta Bustamante) se menciona también la elección de guijarros de calcedonia y madera silicificada para la realización de raspadores utilizados en el trabajo de pieles (Mansur et al. 2000).

\section{Marisma}

La Marisma de bahía Loyola tiene una longitud aproximada de $8 \mathrm{~km}$ y un ancho de casi $3 \mathrm{~km}$ en bajamar, pudiéndose reconocer los tres segmentos típicos de estas geoformas: inferior, medio y superior, cuya edad y cota aumenta en ese sentido ( 5 a $8 \mathrm{~m}$ ) (Perillo et al. 1996) (Fig. 2). En los dos primeros segmentos, diariamente inundados por las mareas, se desarrollan especies vegetales de tipo halófita donde predomina Salicornia ambigua a modo de cobertura más o menos continua. En el superior esta especie se restringe sólo a los canales de marea y cañadones activos, mientras que el resto de la superficie está colonizada por arbustos (Lepidophyllum cupressiforme y Berberis buxifolia) y diversas gramíneas distribuidos en forma de parches entre los que queda expuesto el sustrato limo-arcilloso. La deflación exporta estos sedimentos los que en parte son entrampados por la vegetación y son el sustento de nuevos individuos; ocasionalmente cubren restos arqueológicos.

Bancos de grava arenosa parcialmente vegetados suelen localizarse en la parte distal de la Marisma, a expensas de pulsos de alta energía de olas que ingresaron al estuario en los estadios iniciales de su evolución. Estos bancos se disponen longitudinalmente al resalto del contacto Marisma/Paleoalbufera y Marisma/Cordones litorales II (Fig. 2).

Los hallazgos arqueológicos de esta unidad $(n=342)$ ocurren sólo en el segmento superior. Dentro del conjunto instrumental lo más relevante son dos puntas de proyectil, una en basalto y otra en calcedonia. El diseño de la primera se asemeja a las denominadas Bird IV (Bird 1993) las que en proximidades del estrecho de Magallanes fueron datadas en contextos que corresponden a unos 1900 años AP (L'Heureux y Franco 2002). Mientras que en el curso medio del río Gallegos se las ubica temporalmente ca. 2500 años AP (Gómez Otero 1986/87).
Es llamativo el elevado porcentaje de microlascas contabilizado, las cuales están prácticamente ausentes en el resto de las unidades del área. La recuperación de elementos de dimensiones inferiores a $10 \mathrm{~mm}$ permite inferir una escasa o nula redistribución. Así la presencia de microlascas y de artefactos sin evidencias de abrasión o corrosión hídrica permite suponer la ausencia de flujo de marea sobre el tramo superior de la Marisma. Este hecho que se ve reforzado por la distribución de las especies halófitas restringidas sólo a los canales y por un registro arqueológico expuesto en superficie que implica la ausencia de agradación. Por otra parte, respecto de las posibilidades de enterramiento de los materiales arqueológicos de tamaños grande a pequeño, debe tenerse en cuenta que dadas las similitudes litológicas con la Paleoalbufera se espera un comportamiento semejante entre ambas. No han sido hallados restos óseos que puedan utilizarse como control independiente para dar cuenta de este proceso (cf. Cruz 2001). En relación con lo expuesto, puede suponerse además que se trataría de un conjunto muy reciente. Otros argumentos en favor de la juventud son el bajo porcentaje de pátinas, aun en restos manufacturados en litologías lábiles al ambiente exógeno (basalto), y la falta de evidencia de abrasión eólica.

De acuerdo a lo señalado puede inferirse que el tramo superior de la Marisma alcanzó una elevación suficiente como para limitar el flujo laminar de las mareas al menos desde hace unos 150 años, momento para el cual las crónicas etnohistóricas mencionan a los últimos campamentos aborígenes en el valle del río Gallegos (Musters 1964, entre otros).

En el sector central de la unidad aflora una superficie sobreelevada y acorazada por espigas que no es alcanzada por la marea. Por su litología, diseño de drenaje y cotas podría tratarse de un remante de erosión de la Paleoalbufera. En este último espacio, donde se planteó la T № M2b, se recuperó un único artefacto que corresponde al raspador de calcedonia ya mencionado en la Paleoalbufera.

Los resultados distribucionales para la totalidad de la unidad Marisma, advierten acerca de una tendencia al aumento del orden de magnitud de la densidad de artefactos en sentido O-E. A unos 8,5 $\mathrm{km}$ de la boca del estuario (T № M1) el valor es de $10^{-4}$ ascendiendo a $10^{-2}$ en inmediaciones de Punta 
Loyola (T № M5, M6). Hay una asociación espacial de proximidad entre altas frecuencias y geoformas de litología gruesa, tales como bancos de grava y espigas, poco litificadas y escasamente vegetadas. Se observa además que la frecuencia artefactual decrece sensiblemente a partir de dichos puntos. Los hallazgos se produjeron en sectores desprovistos de vegetación y ocasionalmente se registró material lítico en la cobertura eólica superficial entrampada por los arbustos. El alto porcentaje de UM con hallazgos (62\%) denota que el registro se distribuye en forma más o menos continua. Puede considerarse que las densidades apuntadas son representativas de las reales dado que no existe alteración antrópica y las posibilidades de enterramiento son prácticamente nulas.

\section{Espigas de Punta Loyola}

En el sector oriental de la Marisma y por difracción de olas alrededor de Punta Loyola (Perillo et al. 1996), se depositaron en forma sucesiva, $y$ de $\mathrm{E}$ a $\mathrm{O}$, una serie de cuatro espigas recurvadas que se apoyan sobre ésta y la Paleoalbufera. Están compuestas por gravas caladas medianas a gruesas con escasa matriz arenosa. De las cuatro, la posicionada más hacia el oriente fue denominada Espiga interna. Es la más elevada y de mayor desarrollo edáfico, razón por la cual se la diferencia de las otras tres. A estas últimas se las agrupa bajo la denominación de Espigas externas, debido a que poseen características morfológicas y altimetrías semejantes. La más joven se conecta a una estrecha playa de escasos $8 \mathrm{~m}$ de ancho.

La Espiga interna se sobreeleva aproximadamente $1 \mathrm{~m}$ respecto a las externas y posee a su vez una mayor longitud. Está cubierta en su porción proximal y media por un manto irregular de arena eólica que alcanza un espesor máximo de $50 \mathrm{~cm}$. Posee una densa cobertura arbustiva la que no ha sido impedimento para la visualización de restos arqueológicos. El horizonte superficial del suelo (A) de unos $50 \mathrm{~cm}$, contiene materia orgánica parcialmente degradada y considerable aporte de material eólico. Expuesto en un perfil de cantera y formando parte de la matriz se detectó material lítico hasta una profundidad de $45 \mathrm{~cm}$ en asociación física con restos óseos de guanaco (Lama guanicoe) e invertebrados marinos (Mytilus chilensis y Patinigera magallanica, y una especie de la familia Volutidae). Es de destacar que los invertebrados mencionados no forman parte de la litología de la espiga, razón por la cual se infiere su transporte antrópico (Carballo y Ercolano 2001). En igual sentido, los restos culturales no muestran signos de abrasión hídrica. El fechado por OCR de este horizonte dio una edad preliminar de 306 años cal. AP (OCR Carbon Dating, Inc. /7108), siendo éste un valor de tiempo de residencia media de la materia orgánica y que puede tomarse como una edad mínima para la génesis de esta espiga y máxima para la depositación de los restos arqueológicos.

Entre los artefactos recuperados se destacan los yunques $(n=2)$ manufacturados en andesita y núcleos $(\mathrm{n}=21)$ en basalto y dacita en su mayoría multidireccionales y con reserva de corteza (25-75\%). La alta frecuencia de estos últimos sumado al alto porcentaje de lascas primarias de igual litología orienta a pensar en la realización de actividades de desbaste inicial. Por otra parte, la ausencia de percutores hace suponer que cualquier rodado de dureza suficiente habría cumplido esta función. Se está en presencia de un conjunto sumamente expeditivo en función de la alta disponibilidad de materia prima y de un espacio que habría sido equipado por el uso de manera recurrente.

Para sectores carentes de antropismo, sólo registrados en 6 UM de la T № 14, la densidad artefactual tiene un valor de 5,4 10 ${ }^{-3}$ (recalculada para estas UM). Como consecuencia de la búsqueda de áridos llevada a cabo en la parte proximal y media de la espiga, se exponen materiales arqueológicos que registran los valores de densidad más altos del área de estudio. En el caso de T № $10 \mathrm{aD}$ el orden de magnitud trepa hasta $10^{-1}$. Esta transecta atraviesa numerosos montículos alineados donde se ven mezclados arena eólica, vegetación muerta junto a gravas y suelo de la espiga. Las actividades mencionadas generaron palimpsestos, mientras que la acción del viento produce la alternativa exposición en superficie de los restos culturales.

El 79\% de UM con hallazgos verificados en esta unidad habla de una distribución marcadamente continua del registro arqueológico. La obtención de elevados valores de frecuencia artefactual, aun con porcentajes de vegetación de 75 al 100\%, da la pauta que existe independencia entre cobertura vegetal y visibilidad arqueológica. 


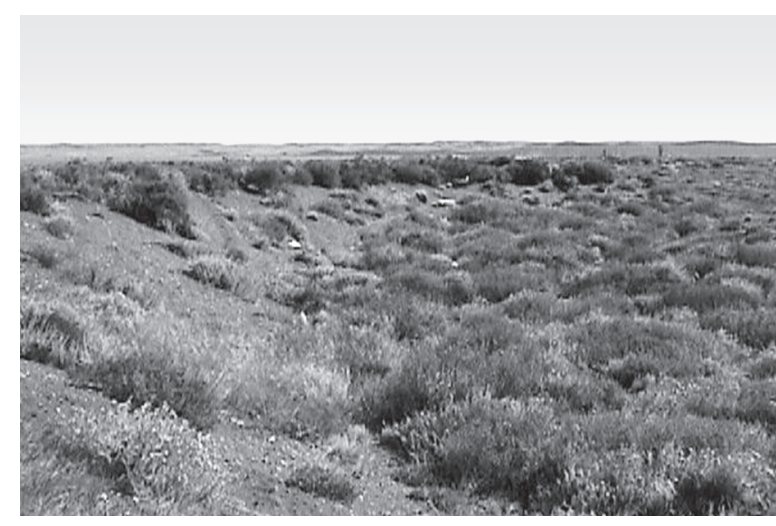

Fig. 3. Vista del flanco oriental de la espiga interna de Punta Loyola.

Las altas densidades y la distribución continua del registro son concordantes con la idea de un uso recurrente de esta geoforma. Estas concentraciones a lo largo de un espacio geográfico acotado parecen ser producto de ocupaciones reiteradas en tiempos muy recientes. Es posible que la morfología relativamente más sobreelevada de la espiga y su cercanía a la línea de costa haya ofrecido por un lado, reparo en un área carente de ellos, y por otro una oferta variada de recursos alimenticios marinos y terrestres, además de materia prima lítica (Fig. 3).

Las Espigas externas, más jóvenes que la interior, tienen cotas que descienden muy suavemente hacia el litoral $(9,50 \mathrm{~m})$ y se elevan 2 a $3 \mathrm{~m}$ por encima de la marisma. Cuentan con escasa vegetación de gramíneas y arbustos en manchones, más densos a mayor lejanía de la costa. Esta cobertura se relaciona con un incipiente e irregular horizonte edáfico de no más de $10 \mathrm{~cm}$ de espesor desarrollado a partir de material eólico limo-arcilloso entrampado en las gravas superficiales y que contiene abundantes fibras vegetales.

La frecuencia artefactual de estas espigas $(n=3)$ corresponde a sectores con alteración nula a total y con una cobertura vegetal altamente variable. Este valor es muy bajo y lo es más aún si se tiene en cuenta que esta unidad es contigua a la Espiga Interna, geoforma con la más alta densidad artefactual y distribución continua del área. Como explicación pueden esgrimirse varios argumentos. En principio, no puede atribuirse una mala visibilidad a la ausencia de hallazgos. Por otro lado, la alta porosidad de las gravas pudo haber favorecido una movilización vertical en sentido descendente de los artefactos, en particular de aquellos con dimensiones medianas a pequeñas. Finalmente, se piensa que la extrema juventud de esta unidad es la razón por la cual no habría estado disponible para ser ocupada por los cazadores recolectores. A partir del fechado obtenido para la espiga interna (306 años AP) y las referencias etnohistóricas para el valle del río Gallegos es posible suponer que las espigas externas hayan evolucionado durante los últimos 200 años. En función de lo expuesto cabría pensar que los 3 artefactos hallados proceden de la espiga interna en virtud del alto antropismo que sufre la zona.

En la playa actual de gravas, que se desarrolla en continuidad espacial con las espigas, no ocurrieron hallazgos arqueológicos, lo que se explica por la juventud de la geoforma.

\section{Sector CLA}

De los $153.000 \mathrm{~m}^{2}$ muestreados provienen los 325 artefactos recuperados.

\section{Cordones de gravas recurvados}

Estos cordones se encuentran circunscriptos a la zona central de Punta Loyola dispuestos en discordancia sobre sedimentitas paleoalbuféricas. Sus cotas varían entre 12,50 y 13,50 m siendo comparables con la de los cordones litorales más elevados de Punta Bustamante, hecho que permite vincularlos cronológicamente ( ca. 6700 AP, González Bonorino 2002). Dada la particular hidráulica que implicó su génesis no ha podido establecerse aún en qué momento fue un espacio potencialmente ocupable por las poblaciones cazadoras recolectoras, es decir, cuándo ocurrió el retiro del agua y el acceso a ellos fue posible. A partir de su evolución edáfica, puede suponerse un mayor tiempo de estabilidad de esta superficie geomórfica comparada con otras unidades de litología similar del área. Los suelos cuentan con un horizonte A de unos $50 \mathrm{~cm}$ de espesor, oscurecido por materia orgánica, con rubificación incipiente en el que participan en gran proporción arenas eólicas.

Dada la constricción espacial de los afloramientos, la muestra fue comparativamente más pequeña que en otras geoformas. No se produjeron hallazgos en transecta, las mismas abarcaron 
sectores con y sin perturbación antrópica (T № 9 y T № 15). Adicionalmente a éstas, se analizaron perfiles expuestos con motivo de la construcción de obras de infraestructura donde tampoco se observó material arqueológico en capa. Este resultado es concordante, como se verá, con los verificados en la Paleoalbufera que aflora en continuidad espacial a estos cordones.

\section{Paleoalbufera}

Este sector de Paleoalbufera, ligado espacialmente al litoral atlántico, posee un relieve llano encontrándose a cotas que oscilan en los $10 \mathrm{~m}$. No hay diferencias litológicas, morfológicas como así tampoco en el tipo y distribución de cobertura vegetal con respecto a la unidad equivalente descripta en CE.

En virtud de estas semejanzas puede esperarse un comportamiento similar del registro arqueológico. Sin embargo aquí, las densidades artefactuales son nulas para sectores con diferente grado de alteración antrópica o como máximo tienen el valor regional ( $\mathrm{T} \mathrm{N}$ ㄴ) $)$. Un pico de densidad con un orden de magnitud de $10^{-2}$ se asocia a 7 UM consecutivas de la $\mathrm{T}$ №3, lo que se interpreta como un sitio arqueológico. Observaciones realizadas fuera de transecta algo más al $\mathrm{S}$ muestran un patrón de distribución semejante, pudiéndosele atribuir el carácter de discreto. El bajo porcentaje de UM con hallazgos $(12,5 \%)$ sustenta la discontinuidad en la utilización de este sector del espacio. Lo más representativo del repertorio artefactual son las lascas de basalto y dacita $(\mathrm{n}=248)$, siendo escasamente significativos los núcleos $(n=2)$ y raederas $(n=2)$, clases más usuales del área. En todos los casos el material recuperado no está en estricta proximidad espacial a geoformas que puedan proveer materia prima lítica, si bien esta última se halla en un radio no superior a $1 \mathrm{~km}$.

En una cantera denominada 099 (Fig. 2), un horizonte de materia orgánica de $1 \mathrm{~cm}$ de espesor cercano al techo de la unidad aportó una edad de $1610 \pm 60$ años ${ }^{14} \mathrm{C}$ AP (1348-1683 años cal. AP - 2 sigmas-) (LATYR LP-1419). En este sector de muestreo la Paleolbúfera infrayace a los Cordones litorales III, de modo que es posible ubicar cronológicamente a estos cordones en el final del Holoceno tardío (ver próximo punto).

\section{Cordones litorales III y Playa del litoral atlántico}

El relieve llano de la paleoalbufera da paso hacia el este a uno de suaves ondulaciones conformado por una serie de cordones litorales apoyados de manera discordante sobre ella, que culminan en una playa de elevada pendiente. Los afloramientos cordoniformes son elongados en sentido meridiano, no superan $1 \mathrm{~km}$ de ancho y se encuentran a cotas comprendidas entre 11 y 12 m. Están compuestos por un agregado de cantos rodados y bloques con matriz arenosa mediana sobre los que se ha desarrollado una cobertura edáfica que sustenta arbustos y gramíneas en buena medida a partir del aporte de arenas eólicas. Suelo y cobertura vegetal tienen una expresión más significativa a mayor distancia de la línea de costa. Ocasionalmente aparecen en superficie o parcialmente enterrados restos desarticulados de cetáceos, pinnípedos, guanaco y aves.

La superficie de esta geoforma se encuentra parcialmente alterada por caminos secundarios y canteras de extracción de áridos. El relevamiento dio resultados dispares, prácticamente no se detectaron restos culturales en los sectores sin alterar o parcialmente alterados. Densidades artefactuales significativas se registraron en dos transectas dirigidas (№ CL1D- № CL2D) planteadas en la cantera 099 abierta en el contacto Cordones Litorales III/Paleoalbufera (Fig. 2). La frecuencia artefactual más alta $(n=63)$ proviene del piso de este laboreo y es producto de una concentración artificial de materiales cuyo resultado es una densidad de 1,1 10-2. La visualización del material se vio favorecida por una conjunción de ausencia de cobertura vegetal y buen contraste granulométrico entre partícula arqueológica y sedimentaria dado que la profundización de la cantera alcanzó el techo de la Paleoalbufera. En las escombreras que circunscriben este laboreo, compuestas por gravas y bloques parcialmente vegetados, el valor de densidad desciende un orden de magnitud. Parece evidente que los materiales recuperados provienen de estos cordones, hecho que no pudo verificarse debido a la existencia de un importante talud en los frentes de avance de la explotación ahora abandonada. El contraste de densidades artefactuales que se advierte entre zonas con distintos grados de impacto antrópico de esta unidad, puede relacionarse con 
las buenas posibilidades de enterramiento debido a la constitución granulométrica de los cordones, como ya fuera descrito para otras unidades de similar litología del área.

La búsqueda de restos culturales en la playa dio resultados negativos y valen las consideraciones realizadas para la playa de CE acerca de su juventud.

\section{CONCLUSIONES}

La regresión marina que comenzó entre los 6000 a 7000 años AP y la posterior estabilización del nivel del mar, posibilitaron la evolución del estuario cuya dinámica dio lugar a casi todas las geoformas del área analizada, a excepción de los Cordones Litorales II (preholocénicos) y los Cordones Litorales III. La edad arriba mencionada puede ser considerada entonces como una edad máxima para la mayor parte del registro arqueológico pudiendo considerarse como edad mínima 150 años, momento para el cual las crónicas dan cuenta de las últimas ocupaciones indígenas en la región (Musters 1964).

De la evaluación del registro arqueológico de CE y CLA se delinea un paisaje que muestra que en todo el espacio se han realizado actividades de talla, preferentemente a partir de nódulos de basalto y dacita que no superan los $10 \mathrm{~cm}$ de diámetro máximo; el tamaño de los artefactos líticos guarda relación con los rodados disponibles en el área. El alto porcentaje de lascas corticales $(\sim 30 \%)$ y de reactivación de núcleo, y de núcleos sobre rodados sin preparación previa, la casi ausencia de talones preparados, filos simples en los instrumentos y el descarte de piezas enteras o con un alto potencial de uso, se vincula con conjuntos expeditivos. Este hecho se debe en primera instancia, a la gran disponibilidad de materia prima que supone una baja inversión de energía en su selección, dando como resultado un uso y abandono en el lugar. Los resultados indican que el basalto compone alrededor del $80 \%$ de la muestra artefactual, seguido por la dacita con un 15\%. El 5\% restante corresponde a diversas litologías entre las que se destacan por su muy buena calidad el ópalo, la calcedonia y la obsidiana verde; esta última, recuperada en la Marisma, es la única alóctona y procede del Seno de Otway (Stern y Prieto 1991; Morello et al. 2001; entre otros). Salvo la andesita para yunques o bolas de boleadora y basaltos de calidad muy buena en bifaces, no habría selección de materia prima para la fabricación de artefactos.

Otra particularidad de todos estos conjuntos es la casi total ausencia de pátinas $(<10 \%)$ a pesar que la materia prima más representada es el basalto, roca altamente susceptible a la alteración exógena. $\mathrm{Al}$ analizar macroscópicamente la totalidad de la muestra, se observa que los filos no están redondeados y no hay signos de abrasión eólica (picoteo). Estas observaciones son argumentos que apoyan la juventud del registro arqueológico.

Las frecuencias artefactuales mostraron diferencias significativas entre CE y CLA. Analizadas superficies aproximadamente equivalentes de cada sector, CE cuadruplica ( $n=1383$ ) los hallazgos producidos en CLA ( $n=325)$ (Tablas 1 y 2). Esta tendencia tiene un inmediato correlato en las densidades artefactuales y en el porcentaje de muestreo con hallazgos, aun si se tienen en cuenta las transectas dirigidas. El registro arqueológico de $\mathrm{CE}$ con picos de densidad de $10^{-1}$ obtenidos en unidades morfoestratigráficas de diferente granulometría y con distintos grados de antropismo, hablaría de la existencia de sitios arqueológicos y de una mayor intensidad de uso de este espacio. Asimismo, este uso más intensivo en unidades tales como la Espiga interna de Punta Loyola, la Marisma y la Paleoalbufera vinculada a $\mathrm{CE}$, orienta a pensar en una redundancia genérica, la cual puede asociarse inicialmente con la presencia de canteras potenciales y a un mayor reparo. De este modo, la evidencia indica que la costa del estuario fue un espacio jerárquicamente más importante que el litoral atlántico. Llama la atención la falta de hallazgos en el sector central de Punta Loyola, paso obligado para el tránsito entre ambas márgenes y lindante en su flanco occidental con el punto de mayor frecuencia artefactual (Espiga interna). Una explicación posible, descartados problemas de muestreo, de visibilidad, de enterramiento y de un posible sepultamiento por fenómenos antrópicos, sería que este espacio fue comparativamente muy poco importante.

No se han registrado hallazgos que indiquen tecnologías especializadas para la obtención y procesamiento de recursos marinos, situación compartida con la margen norte del estuario (Sanguinetti de Bórmida 1981) y Cabo Vírgenes (Borrero y 
Franco 2000). Todo parece indicar una importante homogeneidad en las actividades humanas representadas. Por otra parte, a pesar de tratarse de una ocupación costera y con fechados tan tardíos, están ausentes materias primas alóctonas como el vidrio y el hierro. Su incorporación no se ha verificado a pesar de su disponibilidad y acceso relativamente sencillo a raíz de los naufragios, hecho que llama la atención ya que se han detectado en la margen norte del estuario (cf. Sanguinetti de Bórmida 1981; Miotti 1998).

Si se compara la riqueza artefactual del sector costero estudiado con la obtenida en el valle medio e inferior del río Gallegos, se observa que no difieren. En ambos espacios: lascas, núcleos, raederas y raspadores se ubican en orden descendente de importancia. De manera similar se mantuvieron las tendencias observadas respecto a los tipos y porcentajes de materias primas utilizadas en la elaboración de artefactos (Ercolano et al. 2000).

Lo señalado en los dos párrafos anteriores no es concordante con una de las expectativas planteadas al inicio del trabajo que era la de encontrar una mayor riqueza artefactual en la costa respecto al resto del valle del río Gallegos. Esto se esperaba considerando la alta disponibilidad y densidad de recursos y la acción atemperadora del mar, factores que en su conjunto proporcionarían condiciones más propicias de habitabilidad.

No habrían existido problemas de transitabilidad a lo largo del año, tanto por la morfología superficial llana de toda el área como por las características climáticas. Para la margen norte del estuario, Miotti (1998) propone que en tiempos tardíos habría sido ocupada reiteradamente y durante todo el año, basándose en el análisis de fauna marina y terrestre. En el área de estudio no se cuenta con evidencia arqueofaunística para discutir este punto, si bien existen recursos potencialmente utilizables anualmente. Sin embargo, se presentaría como un problema la disponibilidad de agua potable permanente, la cual sólo se encontraría en los ríos Gallegos y Chico aguas arriba de la influencia de la marea, o sea a una distancia superior a $20 \mathrm{~km}$ de la boca del estuario. La posibilidad de obtenerla de fuentes temporarias pudo haber sido riesgosa en función de la ausencia de cuencas endorreicas de relativa magnitud que pudieran mantener el nivel de agua a lo largo del año. La situación de la margen norte sería diferente habida cuenta de la presencia de grandes bajos sin salida con agua permanente, hecho determinante para la circulación en ambientes semiáridos en épocas de sequías prolongadas. Podría plantearse entonces, que para estos lapsos las poblaciones se movilizaran río arriba donde el recurso fluvial permaneció y donde también fue previsible en bajos profundos como la laguna Azul (cercana al río Chico y a las nacientes del Chorrillo de los Frailes) (Zolitschka et al. 2004) o la laguna Potrok Aike (cuenca media del río Gallegos) (Heberzettl et al. 2005). Hasta el momento, es también difícil evaluar el impacto sobre las poblaciones costeras del pulso frío y húmedo correspondiente a la "Pequeña Edad del Hielo" (Siglo XVI a XIX). No obstante, puede afirmarse que el estuario del río Gallegos estuvo ocupado tal como lo evidencia el fechado OCR obtenido en la espiga interna de Punta Loyola (306 años cal. AP).

La otra expectativa de trabajo acerca de una mayor frecuencia artefactual en unidades más antiguas tampoco se cumplió, dado que una geoforma muy reciente como la Espiga interna posee uno de los valores de densidad más altos (Tabla 1). Puede proponerse entonces, una incorporación tardía y simultánea de todo el espacio estudiado al rango de acción de las poblaciones cazadoras recolectoras en función de las cronologías disponibles y el poco tiempo de exposición del conjunto lítico.

El estudio llevado a cabo indica un uso más intensivo del espacio costero en relación con el resto del valle del río Gallegos y una ocupación más recurrente del estuario versus el litoral atlántico durante el final del Holoceno tardío. No obstante, habría sido un espacio marginal en los circuitos de movilidad de los cazadores recolectores.

\section{AGRADECIMIENTOS}

Los fondos para la realización de los trabajos provienen de subsidios asignados a dos proyectos de investigación (Proyectos 29/A060 y 29/A137) radicados en la Universidad Nacional de la Patagonia Austral - Unidad Académica Río Gallegos, Santa Cruz, Argentina. Agradecemos a Juan Bautista Belardi por la lectura crítica del manuscrito y las sugerencias realizadas, como así también a los dos revisores anónimos. 


\section{BIBLIOGRAFÍA}

ASCHERO, C. A. 1975/revisión 1983. Ensayo para una clasificación morfológica de artefactos líticos aplicada a estudios tipológico-comparativos. Consejo Nacional de Investigaciones Científicas y Técnicas (CONICET). MS.

BARBERENA, R. 2002. Los límites del mar. Isótopos estables en Patagonia meridional. Argentina. Sociedad Argentina de Antropología. Colección Serie Tesis de Licenciatura.

BELARDI, J. B. y L. A. BORRERO. 1999. El paisaje arqueológico de la margen norte del lago Argentino (Provincia de Santa Cruz). Praehistoria 3:35-64.

BIRD, J. 1993. Viajes y Arqueología en Chile Austral. Editado por John Hyslop. Ediciones de la Universidad de Magallanes, Punta Arenas, Magallanes, Chile.

BORRERO, L. A. y N. FRANCO. 2000. Arqueología de Cabo Vírgenes, Provincia de Santa Cruz. Actas del XIII Congreso de Arqueología Argentina, en prensa. Córdoba.

BOYD, R., R. DALRYME y B.A. ZAITLIN. 1992. Classification of clastic coastal depositional environments. Sedimentary Geology, 80:139-150.

CARBALLO, F.; B. ERCOLANO; E. MAZZONI y M. VÁZQUEZ. 2000. Las unidades de paisaje y la distribución de artefactos en el valle inferior del río Gallegos. En: Desde el país de los Gigantes. Perspectivas arqueológicas de Patagonia. Universidad Nacional de la Patagonia Austral (eds.), Río Gallegos, Santa Cruz, pp.: 331-343.

CARBALLO MARINA, F.; J. B. BELARDI; S. ESPINOSA y B. ERCOLANO. 2000. Tecnología y movilidad en el río Coyle, Santa Cruz. Cuadernos del Instituto Nacional de Antropología y Pensamiento Latinoamericano 19: 89-107.

CARBALlO, F, y B. ERCOLANO. 2001. Arqueología de Punta Loyola. XIV Congreso Nacional de Arqueología Argentina. Universidad Nacional de Rosario, Santa Fe. (En prensa).

CARBALLO MARINA, F. y B. ERCOLANO. 2003. La ocupación humana en la margen sur del lago Argentino, Santa Cruz, Argentina. Intersecciones en Antropología 4:45-58.

CARBALLO, F. y B. ERCOLANO. 2004. El uso humano de las marismas del río Gallegos durante el Holoceno. En: Actas de las II Jornadas Patagónicas Mallines y Humedales. Universidad Nacional de la Patagonia Austral, Unidad Académica Río Gallegos (eds.), Santa Cruz. CD-ROM.

CASTRO, A. y J. E. MORENO. 1996-98. Cabo Tres Puntas, un sitio del Holoceno medio en la costa de Patagonia continental. Palimpsesto, Revista de Arqueología 5:135-137.

CASTRO, A. y J.E. MORENO. 2000. Noticias sobre enterratorios humanos en la Costa Norte de Santa Cruz. Anales del Instituto de la Patagonia, Serie Ciencias Humanas, 28:225-233. Punta Arenas, Chile.

CASTRO, A.; E. MORENO; M. ANDOLFO y M. ZUBIMENDI. 2001. Distribución espacial de sitios en la localidad de Punta Medanosa, Santa Cruz (Argentina). Relaciones de la Sociedad Argentina de Antropología, XXVI:303-321.
CASTRO, A.; E. MORENO; M. ANDOLFO; R. GIMÉNEZ; C. PEÑA; L. MAZZITELLI; M. ZUBIMENDI y P. AMBRÚSTOLO. 2003. Análisis distribucionales en la costa de Santa Cruz (Patagonia Argentina): alcances y resultados. Magallania, 31:69-94. Punta Arenas, Chile.

CODIGNOTTO, J.O.; R. KOKOT y S. MARCOMINI. 1992 Neotectonism and sea level changes in the coastal zone of Argentine. Journal of Coastal Research $8(1): 125-133$.

CODIGNOTTO, J. O.; R. R. KOKOT y S. C. MARCOMINI. 1993. Desplazamientos verticales y horizontales de la costa argentina en el Holoceno. Revista de la Asociación Geológica Argentina, 48 (2): 125-132.

CODIGNOTTO, J.O. y B. ERCOLANO. 2002. Cordones litorales pleistocenos al sureste de Río Gallegos, Santa Cruz. En: Actas del XV Congreso Geológico Argentino. Cabaleri N.; C.A. Cingolani; E. Linares, M.G. López de Luchi; H.A. Ostera, y H.O. Panarello (eds.), El Calafate, Santa Cruz, II:595-596.

CORDEAU, E. 1965. Hipótesis preliminar sobre el Epimiolítico final en el extremo sur argentino. Convención Nacional de Antropología (2da. Parte), CNA, Resistencia.

CRUZ, I. 2001. Paisajes arqueológicos y tafonomía en la cuenca del río Gallegos. La conformación del registro óseo actual y su potencial de enterramiento. XIV Congreso Nacional de Arqueología Argentina. Universidad Nacional de Rosario, Santa Fe. (En prensa).

CUADRA, D. E. y G. OLIVA. 1996. Ambientes naturales de la Provincia de Santa Cruz. Espacios 6: 22-28.

CHAPELL J. y C. D. WOODROFFE. 1992. Macrotidal estuaries. En: Late Quaternary shoreline morphodynamics. Coastal Evolution. R.W.G. Carter and C.D. Woodroffe (eds.), Cambridge University Press, Gran Bretaña, pp.: 187-218.

DUNNELL, R y W. S. DANCEY. 1983. The siteless survey: a regional scale data collection strategy. Advances in Archaeological Method and Theory 6: 267-287.

ERCOLANO, B.; F. CARBALLO y E. MAZZONI. 2000. El uso del espacio por parte de las poblaciones cazadorasrecolectoras en la cuenca inferior del Río Gallegos, extremo sur de Patagonia, Argentina. Anales del Instituto de la Patagonia, Serie Ciencias Humanas 30:233-250.

ESPINOSA S.; J. B. BELARDI y F. CARBALLO MARINA. 2000. Fuentes de aprovisionamiento de materias primas líticas en el interfluvio Coyle - Gallegos (Provincia de Santa Cruz). En: Desde el País de los Gigantes. Perspectivas arqueológicas en Patagonia, pp: 5-18. Editado por Universidad Nacional de la Patagonia Austral.

FERUGLIO, E. 1950. Las Terrazas Marinas. En: Descripción Geológica de la Patagonia. Editado por Coni: III:74196, Dirección General de Yacimientos Petrolíferos Fiscales, Buenos Aires.

FRANCO, N. 2002. Estrategias de utilización de recursos líticos en la cuenca superior del río Santa Cruz. Tesis doctoral. Universidad de Buenos Aires. MS.

GÓMEZ OTERO, J. 1986/87. Investigaciones arqueológicas en el alero Potrok Aike (Prov. de Santa Cruz). Una revisión de los períodos IV y $\mathrm{V}$ de Bird. Relaciones de la Sociedad Argentina de Antropología, XVII/ 1.N.S. $173-200$. 
GÓMEZ OTERO, J y M. V. FONTANELLA 1981. Informe sobre una prospección arqueológica en el extremo sur de la Pcia. de Santa Cruz. Karu Kinka 28: 3-15.

GONZÁLEZ BONORINO, G. 2002. Erosión y acreción litoral durante el Holoceno, en especial referencia a las puntas Bustamante y Dungeness. En: Geología y Recursos Naturales de Santa Cruz. M. Haller (ed.). Relatorio del XV Congreso Geológico Argentino, El Calafate, Santa Cruz, Capítulo I-20:317-324.

HEBERZETTL, T., M. FEY, A. LÜCKE, N. MAIDANA, C. MAYR, C. OHLENDORF, F. SCHÄBITZ, G.H. SCHLESE, M. WILLE y B. ZOLITSCHKA. 2005. Climatically induced lake level changes during the last two millennia as reflected in sediments of Laguna Potrok Aike, southern Patagonia (Santa Cruz, Argentina). Journal of Paleolimnology 33:283-302, Springer.

IPCC 2001. Climatic Change 2001: The Scientific Basis. En: Houghton, J.T., Y. Ding, D.J. Griggs, M. Noguer, P.J. van der Linden, X. Dai, K. Maskell and C.A. Johnson (eds.). Contribution of the Working Group I to the Third Assessment Report of the Intergovernmental Panel on Climate Change, Cambridge University Press, Cambridge, United Kingdom and New York, USA, pp. 881

ISLA VERA, M. 2004. La alimentación de Odontesthes smitti durante la primavera de 2001 en el estuario del río Gallegos (Santa Cruz). Resúmenes II Jornadas patagónicas de Mallines y Humedales, pp: 37. Universidad Nacional de la Patagonia Austral. Unidad Académica Río Gallegos. Río Gallegos, Santa Cruz.

JMB-JICA 2004. Estudio para la Gestión Ambiental de la Ría de Río Gallegos. Informe Final, en CD-Rom, Río Gallegos, pp. 506.

KOKOT, R y J. O. CODIGNOTTO. 2002. Geomorfología de la faja litoral de la Provincia de Santa Cruz. En: Actas del XV Congreso Geológico Argentino. Cabaleri N.; C.A. Cingolani; E. Linares, M.G. López de Luchi; H.A. Ostera, y H.O. Panarello (eds.), El Calafate, Santa Cruz, Tomo II:524-528.

LHEUREUX, G. L. y N. FRANCO. 2002. Ocupaciones Humanas en el área de Cabo Vírgenes (Pcia. de Santa Cruz, Argentina): El sitio Cabo Vírgenes 6. Anales del Instituto de la Patagonia, Serie Ciencias Humanas 30:183-201, Punta Arenas, Chile.

LHEUREUX; G. L. GUICHÓN; R., BARBERENA y L. BORRERO. 2003. Durmiendo bajo el faro. Estudio de un entierro humano en Cabo Vírgenes (C.V.17), Pcia. de Santa Cruz, República Argentina. Intersecciones en Antropología 4:87-97.

MANSUR-FRANCHOMME, M. E. 1988. Estudios arqueológicos en sitios costeros al norte del río Gallegos, Pcia. de Santa Cruz: la zona de Punta Bustamante. Resúmenes IX Congreso Nacional de Arqueología Argentina, p. 5.

MANSUR M. E.; D. MARTINIONI y A. LASA. 2000. La gestión de los recursos líticos en el sitio Marina 1 (zona central de Tierra del Fuego, Argentina). En: Desde el país de los Gigantes. Perspectivas arqueológicas en Patagonia Universidad Nacional de la Patagonia Austral (eds.), Río Gallegos, Santa Cruz, pp: 57-72.

MANSUR, M.E., D. LASA y M. VÁZQUEZ. 2005. Investigaciones arqueológicas en Punta Bustamante, provincia de Santa Cruz: el sitio RD01BK. En: Contra viento y marea. Arqueología de Patagonia. Compiladores: M. T. Civalero, P. Fernández y A.G. Guráieb, Instituto Nacional de Antropología y Pensamiento Latinoamericano. Sociedad Argentina de Antropología, pp: 755-774, Buenos Aires.

MAZZONI, E.; E. RUIZ POSSE y M. VÁZQUEZ. 2003. Variación interanual de los cuerpos de agua en el sur de Santa Cruz. En: Actas II Jornadas patagónicas de Mallines y Humedales. Universidad Nacional de la Patagonia Austral. Unidad Académica Río Gallegos (eds.), Santa Cruz, CD-ROM.

MIOTTI, L. 1998. Zooarqueología de la meseta central y costa de Santa Cruz. Un enfoque de las estrategias adaptativas aborígenes y los paleoambientes. Revista del Museo de Historia Natural de San Rafael, Tomo $\mathrm{X}(1 / 4) 3-306$.

MIOTTI, L. 2000. Localidad arqueológica Piedra Museo. En: L. Miotti, R. Paunero, M. Salemme y G.R. Cattaneo (eds.). Guía de campo de la visita a las localidades arqueológicas. Taller Internacional del INQUA, "La colonización del sur de América durante la transición Pleistoceno-Holoceno". Pp.:55-78.

MORELLO, F.; M. SANROMÁN; A. PRIETO y CH. STERN. 2001. Nuevos antecedentes para una discusión arqueológica en torno a la obsidiana verde en Patagonia Meridional. Anales del Instituto de la Patagonia. Serie Ciencias Humanas 29:129-148. Punta Arenas, Chile.

MORENO, E.; A. CASTRO y F. PEPE. 2000. El rompecráneo: un artefacto probablemente destinado para la caza de pinnípedos, en la costa de Patagonia continental. En: Universidad Nacional de la Patagonia Austral (eds.). Desde el país de los Gigantes. Perspectivas arqueológicas en Patagonia. Tomo I:563-572.

MUSTERS, G. 1964. Vida entre los Patagones. Un año de excursiones por tierras no frecuentadas, desde el estrecho de Magallanes hasta el río Negro. Biblioteca Centenaria, Tomo I:127-338. Universidad Nacional de la Plata.

NAMI, H. G. 1995. Archaeological Research in the Argentinean Río Chico Basin. Current Anthropology 36(4): 661-664.

PERILLO, G.; M. D. RIPLEY; M.C. PICCOLO y K.R. DYER. 1996. The Formation of Tidal Creeks in the Salt Marsh: New Evidence from the Loyola Bay Salt Marsh, Río Gallegos Estuary, Argentina. Mangroves and Salt Marshes 1 (1): 37-46.

PETHICK, J. S. 1992. Saltmarsh geomorphology. En: Salymarshes: morphodynamics, conservation and engeneering significance. Allen, J.R.L. \& K. Pye (eds.). Cambridge University Press, Gran Bretaña, pp.: 41-62.

RIVAS V. y A. CENDRERO. 1995. Chapter 20: Human Influence in a Low-Hazard Coastal Area: An Approach to Risk Assessment and Proposal of Mitigation Strategies. Journal of Coastal Research Special Issue 12: Coastal Hazards, pp: 289-298.

ROSTAMI, K.; W., R. PELTIER y A. MANGINI. 2000. Quaternary marine, sea level changes and uplift history of Patagonia, Argentina: comparisons with predictions of the ICE-4G (VM2) model of the global process of glacial isostatic adjustment. Quaternary Science Reviews 19:1495-1525. 
SANGUINETTI DE BÓRMIDA, A. 1981. Introducción a la Prehistoria de la Patagonia argentina. UBA, Facultad de Filosofía y Letras. Tesis de doctorado. MS.

SOIL SURVEY STAFF. 1975. Soil Taxonomy: a basic system of soil classification for making and interpreting soil surveys. Agriculture Handbook, № 436. United States, Dep. of Agriculture.

STERN, CH. y A. PRIETO. 1991. Obsidiana verde de los sitios arqueológicos en los alrededores del Seno Otway, Magallanes, Chile. Anales del Instituto de la Patagonia. Serie Ciencias Humanas 20:139-144. Punta Arenas, Chile.

WATERS, M.R. 1996. Principles of geoarchaelogy a North American perspective. University of Arizona Press (eds.), USA.
YESNER, D. 1980. Maritime hunter-gatherers: ecology and prehistory. Current Anthropology 21 (6): 727-750, Chicago.

ZOLITSCHKA, B., SCHÄBITZ, F., LÜCKE, A., WILLE, M., MAYR, C., OHLENDORF, C., ANSELMETTI, F., ARIZTEGUI, D., CORBELLA, H., ERCOLANO, B., FEY, M., HABERZETTL, T., MAIDANA, N., OLIVA, G., PÁEZ, M. y SCHLESE, G.H. 2004. Climate Changes in Southern Patagonia (Santa Cruz, Argentina) inferred from lake sediments - The multi-proxy approach of SALSA. PAGES News, 12 (2):9-11. 